\title{
Biotechnological Potential of Niobium
}

\author{
Parreira $\mathrm{AG}^{1,2 *}$, Carmo $\mathrm{YC}^{1}$ and Souza $\mathrm{HD}^{1}$ \\ ${ }^{1}$ University of the State of Minas Gerais, Brazil \\ ${ }^{2}$ Federal University of Sao Joao Del Rei, Brazil
}

*Corresponding author: Parreira AG, University of the State of Minas Gerais, Divinopolis MG Unit, Brazil And Federal University of Sao Joao Del Rei-Campus CCO, Divinópolis MG, Brazil.

Received Date: November 18, 2019

Published Date: November 26, 2019

\section{Mini Review}

The Niobium metal received this denomination in honor of Tantalus's daughter (King of Greek Mythology), named Niobe. It was discovered in 1801 by Hatchett, and the Niobium nomenclature adopted by IUPAC in 1950. Niobium is not found in nature in a free condition, usually associated with the tantalo mineral [1]. Brazil holds the world's largest niobium reserves, followed by Canada (provinces of Quebéc and Ontario), Australia (Province of Western Australia), Egypt, Democratic Republic of congo, Greenland (territory belonging to Denmark), Russia (Siberia, Republic of Yakútia), Finland, Gabon, Tanzania, among others. It is also the world's largest producer of the substance accounting for more than $98 \%$ of the world total. The lavifiable reserves of niobium in Brazil are in the states of Minas Gerais, Amazonas, Goiás, Rondônia and Paraíba [2]. Niobium-containing materials have gained prominence in recent decades due to their special applications in high-tech industries especially in the aerospace sectors with metal superalloys and electronics in which they are widely used as microcapacitors. The virtually irreplaceable use of these materials in strategic sectors makes niobium a crucial element for industrial development in the coming decades being officially defined as critical raw material for the industries European Union and USA. Although the niobium processed in the form of iron-niobium alloy and other products such as niobium oxide is already commercialized in order to add value the Brazilian Ministry of Mines and Energy recommends expanding and disseminating the use of niobium in the country by steel and metallurgical industries in addition to fostering through research the development of new products and compounds for use in health, special metals, optical, aeronautical, aerospace, automotive and technology sectors [3]. Among niobium oxides niobium pentoxide ( $\mathrm{Nb205}$ ) deserves special prominence being a ceramic material of great interest in several areas of study. It presents chemical and physical properties that make it promising in various technological applications, such as catalyst in various types of reactions (esterification, hydrolysis, condensation), gas sensor, semiconductor element in solar cells sensitized by dyes, electronic components and, above all, as a photocatalyst [4]. Regarding the biological properties of niobium there are few reports in the literature that deal with this theme however with very promising results, highlighted by its low toxicity and wide possibilities of applications in biomaterials given their excellent biocompatibility. As an example of biotechnological application of niobium stand out the works developed by Balbinot et al. (2019) that evaluated the bone healing with niobium-containing bioactiveglass composition in rat femur model and concluded that Niobium-containing bioactive glasses promoted bone formation comparable to that of the autogenous bone without compromising the quality of the formed bone [5]. Wei et al. (2019), in turn, concluded that addition of $\mathrm{Nb}$ or $\mathrm{Nb}-\mathrm{Ag}$ could significantly increase the compressive strength and fracture toughness of hydroxyapatite, in addition in vitro and in vivo furthers evaluations showed that $\mathrm{Nb}$ could promote osteoblast proliferation, increase the osteogenic and differentiation enhance the osteointegration ability [6]. Oliveira et al. (2018) showed that peroxoniobium inhibits leukemia cell growth [7]. Pradhan et al. (2017) evaluated the efficacy of antibiotic doped niobium oxide coatings on 316L prepared by incipient wetness impregnation and concluded that that the presence of erythromycin containing niobium coatings on stainless steel helped improve the bacterial resistance in comparison to bare UC-SS which showed a lack of any bactericidal activity [8]. Helali et al. (2008) evaluated the functionalization of niobium electrodes for the construction of impedimetric biosensors and concluded that impedance spectroscopy was successfully applied for the direct monitoring of antibody-antigen interactions using an hexanocyanoferrate(II)/ (III) mixture as a redox probe allowing detection of atrazine at 
concentration level of as low as $50 \mu \mathrm{g} / \mathrm{ml}$, applying functional immunosensors based on Fab fragment k47 antibody grafted on $\mathrm{Nb} / \mathrm{NbO} 2$ electrodes [9].

Regarding the antimicrobial potential of niobium metal Vaidya et al. (2019) observed a minimum bactericidal concentration for niobium metal ion solutions of $15.62 \mathrm{mg} \mathrm{mL}-1$ to Acinetobacter baumannii and $46.87 \pm 11.04 \mathrm{mg} \mathrm{mL}-1$ to Klebsiella pneumoniae [10]. The addition of niobium to copper (3.8\%) has been shown to decrease the bacterial count by up to $99 \%$ against E. coli using viable bacterial count test [11]. Samuel et al. (2016) demonstrated that the newly developed orthodontic adhesive with addition of $20 \mathrm{wt} \%$ TAT and 5w\% PIG-Nb exhibited antibacterial activity in studies on effects of adhesive containing tria and niobium pentoxide phosphate inverted glass [12]. In this context it is worth mentioning that the appearance of antimicrobial drug resistance is one of the great modern challenges of the world's health systems, and reports on bacterial isolations that were admittedly sensitive to drugs used in routine are frequent but that have become resistant to all or almost all drugs available on the market [13]. There are a number of pathogens that are demonstrating increasing resistance from the biocidal action of antimicrobial agents, producing a new mode of pathogenesis [14]. Thus, the World Health Organization (WHO) began to encourage the search for new antimicrobials capable of responding to threats of multidrug-resistant bacterial strains isolated in various locations on the planet, and niobium is a potential metal whose biological properties were little studied or explored. Yuan and Wei (2013) demonstrated that adding $0.1 \%$ $(\mathrm{w} / \mathrm{v})$ of niobium to stainless steel containing niobium significantly improved the antimicrobial effect of that material in the face of a strain of Staphylococcus aureus [15]. Preliminary results from our work have shown the antimicrobial potential of ionic niobium oxide solutions against Proteus mirabilis Figure 1 and Bacillus subtilis by disk diffusion testing using $10 \mu \mathrm{L}$ of niobium solutions to $2 \mathrm{mg} . \mathrm{mL} 1$. Additive and synergistic effects obtained from the association with silver nanoparticles, antibiotics and bisurfactants open relevant perspectives regarding the antimicrobial potential of niobium oxides (Figure 1).

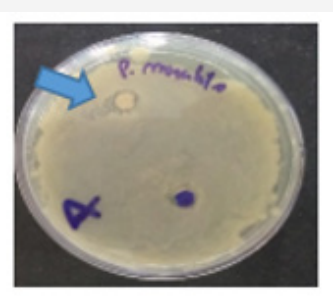

Figure 1: Arrow showing inhibition halo against Proteus mirabilis in disc with $1 \mathrm{mg} \mathrm{mL}-1$ of niobium oxide solution.

\section{Conclusion}

Based on the above and the preliminary results obtained, it can be concluded that the biotechnological potential of the still unexplored niobium metal demonstrates the great potential to study its biological effects yet to be investigated.

\section{Acknowledgement}

UEMG-Unit Divinópolis MG and CNPq Brazil.

\section{Conflict of Interest}

No conflict of interest.

\section{References}

1. Nowak I, Ziolek M (1999) Niobium compounds: preparation, characterization and application in heterogeneous catalysis. Chem Rev 99(12): 3603-3624.

2. DNPM - National Department of Mineral Production- NIÓBIO - Mineral Summary 2014 - Rui Fernandes Junior.

3. Lopes OF, Mendonça VR, Paris EC, Ribeiro C (2015) Niobium oxides: a view on $\mathrm{NB}_{2} \mathrm{O}_{5}$ synthesis and its application in heterogeneous photocatalysis. Quim New 38(1): 106-117.

4. Patil MP, Kim GD (2017) Eco-friendly approach for nanoparticles synthesis and mechanism behind antibacterial activity of silver and anticancer activity of gold nanoparticles. Appl Microbiol Biotechnol 101(1): 79-92.

5. Balbinot GS, Leitune VCB, Ponzoni D, Collares FM (2019) Bone healing with niobium-containing bioactiveglass composition in rat femur model: A micro-CT study. Dental Materials 35(10): 1490-1497.

6. Wei P, Fang J, Fang L, Wang K, Lu X, et al. (2019) Novel niobium and silver toughened hydroxyapatite nanocomposites with enhanced mechanical and biological properties for load-bearing bone implants. Applied Materials Today 15: 531-542.

7. Oliveira LCA, Elene PMC, Ivina PN, Kelen JRC, Alexandre CA, et al. (2018) Peroxoniobium inhibits leukemia cell growth. RSC Advances 8: 1031010313.

8. Pradhan D, Wren AW, Mellott NPA (2017) Preliminary study into the efficacy of antibiotic doped niobium oxide coatings on 316L prepared by incipient wetness impregnation and sol-gel synthesis. Materials Letters 150-153.

9. Helali S, Abdelghani A, Hafaiedh I, Martelet C, Prodromidis MI, et al. (2008) Functionalization of niobium electrodes for the construction of impedimetric biosensors. Materials Science and Engineering C 28(5,6): 826-830.

10. Vaidya M, Mcbain AJ, Banks CE, Whitehead KA (2019) Single and combined antimicrobial efficacies for nine metal ion solutions against Klebsiella pneumoniae, Acinetobacter baumannii and Enterococcus faecium. International Biodeterioration \& Biodegradation 141: 39-43.

11. Baena MI, Márquez MC, Matres V, Botella J, Ventosa A (2006) Bactericidal activity of copper and niobium-alloyed austenitic stainless steel. Curr Microbiol 53(6): 491-495.

12. Samuel SMW, Altmann ASP, Collares FM, Leitune VCB, Arthur RA, et al. (2016) In vitro antibacterial and remineralizing effect of adhesive containing triazine and niobium pentoxide phosphate inverted glass. Clin Oral Invest 21(1): 93-103.

13. Sakagami Y, Kajamura K (2006) Bactericidal activities of desinfectants against vancomycin-resistant Enterococci. Journal of Hospital Infection 50(2): 140-144.

14. Pendleton JN, Gorman SP, Gilmore BF (2013) Clinical relevance of the ESKAPE pathogens. Expert Rev. Anti-infect. Ther 11(3): 297-308.

15. Yuan J, Wei L (2013) Antibacterial 316L Stainless Steel Containing Silver and Niobium. Rare Metal Materials and Engineering 42(10): 2004-2008. 